\title{
The effects of marital status transitions on alcohol use trajectories
}

\author{
Hui Liew \\ Mississippi State University \\ hpliew104@gmail.com
}

(Received November 2011 Revised May 2012)

\section{Abstract}

This study aims to exploit the longitudinal nature of the US Health and Retirement Study (HRS), using a semi-parametric mixture modeling (SPMM) approach to examine whether the presence of marital transitions has an impact on alcohol use trajectories among the elderly. The empirical work of this study is based on the 1994-2008 Health and Retirement Study (HRS). Findings provide support to the marriage protection effect: for both elderly men and women, remaining divorced or widowed had detrimental effects on alcohol consumption. Findings also concur with the potential roles of assortive mating / marital homophily: having a drinking spouse increased alcohol consumption.

\section{Introduction}

For the past few decades, most researchers have discussed, but few have explicitly tested, the potential roles of marriage protection and assortive mating / marital homophily on subsequent alcohol consumption as an explanatory mechanism. The protective mechanism underscores the social integrative function of marriage and the role of social control over risk-taking behavior. As such, being married is a way of gaining increased protection against adverse health outcomes, and marriage has a protective effect in reducing the risk of substance abuse. The assortive mating / marital homophily mechanism implies that marriage can offer individuals a shared lifestyle (Pienta \& Franks, 2006). As such, alcohol consumption may also decrease following the loss of a spouse, especially in the case of the loss of a drinking partner.

Findings pertaining to the marriage protection scenario found inconclusive results. On one hand, proponents of the marriage protection effect have found that transition to marriage reduces alcohol consumption, while transition out of marriage results in increased alcohol consumption (e.g. Bachman, Wadsworth, O'Malley, Schulenberg, \& Johnston,
1997; Hajema \& Knibbe, 1998; Chilcoat \& Breslau, 1996; Leonard and Rothbard, 1999; Miller-Tutzauer, Leonard, \&Windle, 1991; Power \& Estaugh, 1990). Previous studies have found that married individuals have decreased alcohol use (Harford, Hanna, \& Faden, 1994) and steeper rates of decline in alcohol use over time (Curran, Muthen, \& Harford, 1998). More recent research by Bogart and her colleagues (2005) found that women who married as young adults were less likely than singles to engage in any alcohol use, heavy episodic drinking, or experience negative consequences, and reported less alcohol use at age 29. Women who married in adolescence (if they had not divorced) consumed less alcohol and were either less likely to engage in heavy episodic drinking (Bogart, Collins, Ellickson, Martino, \& Klein, 2005). The impact of remarriage and widowhood has also been highlighted. Divorced women who remarried, drank less than those who did not remarry (Prescott \& Kendler, 2001). Relative to men who stayed married over four years, men who became widowed increased their alcohol consumption (Eng, Kawachi, Fitzmaurice, \& Rimm, 2005). Indeed, according to Leonard and Rothbard (1999), marriage 
ushers in a change in social and recreational activities that can lead to a reduction in alcohol consumption, particularly heavy drinking. Some of these studies found that the protection effect of marriage is stronger among women (Bachman et al., 1997) and Whites (Curran et al., 1998).

On the other hand, other researchers have challenged the marriage protective effect. Early opponents of this effect have provided strong support for increased alcohol consumption following marital dissolution. Still, other researchers as early as the mid-1980s (e.g. Jacob \& Bremer, 1986; Yamaguchi \& Kandel, 1993) have acknowledged the potential roles of assertive mating / marital homophily, where individuals tended to select spouses or partners with similar drinking patterns. Indeed, earlier research (Wilsnack, Klassen, Schur, \& Wilsnack, 1991), found that post-dissolution alcohol consumption was lower among women who transitioned out of marriage. They attributed their finding to the possibility that these women were problem/heavy drinkers and they were removed from their heavy-drinking spouses following marital dissolution (Wilsnack et al., 1991). Evidence in France revealed that divorcees and widows drank less than married women, as measured by fewer glasses per day and fewer days per week drinking wine (Zins, Gueguen, Leclerc, \& Goldberg, 1991). Likewise, getting married was accompanied by an increased level of drinking, especially of wine, beginning a year before the wedding and lasting until 4 years after it (Zins et al., 1991). Unfortunately, as shown in Table 1, even though research on the effect of marital transition on alcohol consumption began as early as the 1980s, most existing research tends to focus on young adults (e.g. Bachman et al., 1997; Chilcoat \& Breslau, 1996; Power \& Estaugh, 1990; Power, Rodgers, \& Hope, 1999). Other studies were region-specific (e.g. Bogart et al., 2005; Hajema \& Knibbe, 1998; Matzger, Delucchi, Weisner, \& Ammon, 2004). To the best of my knowledge, only four studies have examined the marriage effect later in life using repeated measure approaches (e.g. Eng et al., 2005; Miller-Tutzauer et al., 1991) and latent growth models (e.g. Curran et al., 1998; Prescott \& Kendler, 2001). On one hand, the risk of alcohol consumption may increase following marital transition, as separated / divorced or widowed individuals may view drinking as a way of to cope with their loss and to reduce stress, especially in the initial months of separation and widowhood. On the other hand, alcohol consumption may also decrease following the divorce, separation, or widowhood, especially if the spouse was a drinking partner, as marriage can offer individuals a shared lifestyle (Pienta \& Franks, 2006). This is especially true for females who were married to a male alcoholic (Brennan, Moos, \& Kim, 1993).

Alcohol use among the elderly has increasingly become a common but unrecognized problem among health practitioners and policy makers (Dar, 2006) but there is still a scarcity of knowledge regarding the impact of marital transition on alcohol consumption later in life. To fill this research gap, this study aims to exploit the longitudinal nature of the Health and Retirement Study (HRS) to examine whether the presence of marital transitions has an impact on alcohol use trajectories among the elderly. 
Table 1. Findings on the impact of marital status on alcohol consumption

\begin{tabular}{|c|c|c|c|c|}
\hline Author & Age & Setting & Statistical Method & Dataset / Subjects \\
\hline Bogart et al., 2005 & $\begin{array}{l}\text { 1,138 women aged } \\
18-29 .\end{array}$ & $\begin{array}{l}\text { U.S. (middle } \\
\text { schools in } \\
\text { California and } \\
\text { Oregon) }\end{array}$ & Not provided & $\begin{array}{l}\text { Data were } \\
\text { collected at age } 13 \\
\text { and respondents } \\
\text { were followed from } \\
\text { ages } 18 \text { to } 29 .\end{array}$ \\
\hline $\begin{array}{l}\text { Brennan et al., } \\
\text { (1993) }\end{array}$ & $\begin{array}{l}\text { Late middle-age } \\
\text { women }(\mathrm{N}=183) \\
\text { and men }(\mathrm{N}=476) \text {. }\end{array}$ & U.S. & Not provided & Not provided \\
\hline Curran et al., 1998 & $\begin{array}{l}4,052 \text { men and } \\
\text { women at least } 21 \\
\text { of age in } 1982 .\end{array}$ & U.S. & $\begin{array}{l}\text { Random coefficient } \\
\text { latent curve models }\end{array}$ & $\begin{array}{l}\text { National } \\
\text { Longitudinal Survey } \\
\text { of Youth 1982-1985. }\end{array}$ \\
\hline Dar (2006) & Not provided & England & Not provided & Not provided \\
\hline Eng et al., 2005 & $\begin{array}{l}38,865 \text { men aged } \\
40-75\end{array}$ & U.S. & $\begin{array}{l}\text { Multivariate linear } \\
\text { regression } \\
\text { performed on } \\
\text { repeated measures } \\
\text { for marital status } \\
\text { and health } \\
\text { behaviors. }\end{array}$ & $\begin{array}{l}\text { Longitudinal data } \\
\text { with collected at 4- } \\
\text { year intervals } \\
\text { (1986-90; 1990-94). }\end{array}$ \\
\hline $\begin{array}{l}\text { Hajema \& Knibbe, } \\
1998\end{array}$ & $\begin{array}{l}1,327 \text { men and } \\
\text { women aged 16-69. }\end{array}$ & $\begin{array}{l}\text { Limburg, } \\
\text { Netherlands }\end{array}$ & Not provided & Not provided \\
\hline $\begin{array}{l}\text { Matzger et al., } \\
2004\end{array}$ & $\begin{array}{l}600 \text { dependent and } \\
992 \text { problem } \\
\text { drinkers (men and } \\
\text { women). }\end{array}$ & North Carolina & $\begin{array}{l}\text { Nested models } \\
\text { using maximum } \\
\text { likelihood } \\
\text { estimation }\end{array}$ & $\begin{array}{l}\text { Participants were } \\
\text { interviewed at } \\
\text { baseline and again } \\
1,3,5 \text {, and } 7 \text { years } \\
\text { later }\end{array}$ \\
\hline $\begin{array}{l}\text { Miller-Tutzauer et } \\
\text { al., } 1991\end{array}$ & $\begin{array}{l}80,944 \text { women } \\
\text { aged } 46-71 .\end{array}$ & U.S. & $\begin{array}{l}\text { Repeated- } \\
\text { measures } \\
\text { MANCOVA } \\
\text { (Multivariate } \\
\text { Analysis of } \\
\text { Variance) } \\
\end{array}$ & $\begin{array}{l}\text { Youth Cohort of the } \\
\text { National } \\
\text { Longitudinal Survey } \\
\text { of Labor Market } \\
\text { Experience. }\end{array}$ \\
\hline Author & Age & Setting & Statistical Method & Dataset / Subjects \\
\hline Power et al. 1999 & $\begin{array}{l}35 \text { men and } 20 \\
\text { women aged } 23-33 .\end{array}$ & England & Not provided & $\begin{array}{l}1958 \text { British birth } \\
\text { cohort. }\end{array}$ \\
\hline $\begin{array}{l}\text { Prescott \& Kendler } \\
2001\end{array}$ & $\begin{array}{l}1,986 \text { female twins } \\
\text { aged between } 17- \\
61\end{array}$ & Not provided & $\begin{array}{l}\text { Latent growth } \\
\text { models }\end{array}$ & $\begin{array}{l}\text { Data were } \\
\text { collected between } \\
1-3 \text { waves over } 8 \\
\text { years. }\end{array}$ \\
\hline $\begin{array}{l}\text { Wilsnack et al., } \\
1991\end{array}$ & Not provided & Not provided & Not provided & $\begin{array}{l}1981 \text { national } \\
\text { survey of women's } \\
\text { drinking }\end{array}$ \\
\hline Zins et al. 2003 & 4,782 women & France & Not provided & $\begin{array}{l}\text { Data were } \\
\text { collected and } \\
\text { followed up over a } \\
\text { 5-year period. }\end{array}$ \\
\hline
\end{tabular}




\section{Method}

\section{Subjects}

The empirical work of this study is based on seven waves (1994-2008) of the Health and Retirement Study (HRS). The HRS, which is a collaborative effort between the United States (US) Social Security Administration (SSA) and the National Institute on Aging (NIA) at the National Institutes of Health (NIH), has been the principal source of health data on the advanced age population (50 and over) in America. The HRS is an ongoing longitudinal survey with a high re-interview rate. In addition to providing current information on gender, age, race, self-reported health status, marital status, personal income, and education, individuals participated in in-depth interviews about health behaviors, health care utilization and costs, housing, income, assets, employment status and history, physical and mental health, insurance coverage, financial status, family structure, family support systems, labor market status, and retirement planning. The analysis is limited to elderly men and women whose information on alcohol use, marital history, drinking behavior of the spouse, age, sex, ethnicity, education, depression, and chronic illness is available. The final analysis sample consists of 11,742 elderly men and 15,482 elderly women.

\section{Measures}

The outcome variable alcohol consumption, is computed from responses to questions on the number of drinks consumed on a typical day. I used information from marital histories to create dummy variables for always married (reference), continuously divorced or separated, continuously widowed, never married, and transitioned to marriage from singlehood, divorce or widowhood. These variables are constructed by following respondents at each wave of the survey.

Both time-constant and time-varying control variables were included as control variables. Timeconstant covariates included age, gender, education, spouse was ever a drinker, and pattern of attrition. Age is treated as a continuous variable. Gender is formulated as a dichotomy for males and females (reference). Respondent's race is indicated by dummy variables for White/Caucasian (reference), Black / African-American, and Hispanics. Education is indicated by dummy variables for less than high school, high school or GED (General Education Development) (reference), and greater than high school. Spouse was ever a drinker is a dummy variable, coded as 1 if the spouse reported having consumed alcohol.

Like any other longitudinal studies of older adults, HRS faces the possibility of attrition (primarily due to death and loss at follow-up). Following Vandecasteele and Debels (2007), pattern of attrition will be classified into Always Participating, Monotone Participation, and Variable Participation. Always Participating refers to non-attritors. Individuals who were deceased or loss at follow up are considered monotone attritors. Individuals who are in some waves but not other waves are considered variable participants. The implications of attrition might differ across nonattritors, monotone attritors, and variable participants.

Time varying covariates included comorbidity (i.e. the number of chronic health conditions) and depression. The former is a continuous variable measuring the co-occurrence (sum of) of multiple diagnosed health conditions in an individual within a year. The illnesses included are hypertension, diabetes, cancer, lung disease, heart disease stroke, psychiatric problems, and arthritis. The latter is derived from a mental health index using a score based on the Center for Epidemiologic Studies Depression (CESD) scale. The CESD score, originally developed by Lenore Radloff of Utah State University, is a self-report scale designed to help an individual to determine his or her depressive feelings and behaviors (Radloff, 1977). In the Health and Retirement Study, it is calculated by summing five "negative" indicators and subtracting two "positive" indicators (St. Clair, Blake, Bugliari, Chien, Hayden, Hurd, Ilchuk, Kung, Miu, Panis, Pantoja, Rastegar, Rohwedder, Roth, Carroll, \& Zissimopoulos, 2010). The negative indicators measure whether the respondent has experienced depressive sentiments all or most of the time (St. Clair et al., 2010). The five negative indicators ask respondents if they 1 ) feel depressed, 2) feel that everything they did is an effort, 3) slept restlessly, 4) feel alone, 5) feel sad, or 6) feel like they could not get going (St. Clair et al., 2010). The positive indicators measure whether the respondent felt happy and enjoyed life, all or most of the time (St. Clair et al., 2010). 


\section{Method of Analysis}

Group-based modeling is a type of latent class growth analysis, and was pioneered by Daniel Nagin and Kenneth Land in 1993. It is used to describe and identify the trajectories, patterns, and changes over time in alcohol use among the elderly men and women. Unlike the other longitudinal data analysis techniques such as the hierarchical or growth curve models, it does not assume a monotonic and regularly varying growth in the overall population (Jones, Nagin, \& Roeder, 2001; Nagin, 2005). Instead, it uses a probability function and a semi-parametric mixture modeling (SPMM) approach to classify and assign individuals to their distinctive drinking trajectories based on the patterns of their longitudinal trajectories (Jones et al., 2001). It assumes a number of discrete classes with varying "growths" or trajectories of change, each having a fixed intercept and slope and an estimate of population prevalence (Jones et al., 2001). Under this approach, clusters of individuals with similar developmental trajectories of alcohol consumption over time were identified using the PROC TRAJ procedure in SAS procedure. The likelihood functions of the finite mixture model are formulated by summing $J$ finite number of group-specific, or conditional functions, $p^{j}\left(Y_{i}\right)$ that compose the population, $Y_{i}$ :

$p\left(Y_{i}\right)=\sum_{j}^{J} \pi_{j} p^{j}\left(Y_{i}\right), \quad$ where $\quad p\left(Y_{i}\right)$ is the unconditional probability of observing individual i's longitudinal alcohol use trajectories, $Y_{i}, p^{j}\left(Y_{i}\right)$ is the probability of $Y_{i}$ given membership in group J. It is formulated by $p^{i}\left(Y_{i}\right)=\prod^{T} p^{j}\left(y_{i t}\right)$, where $p^{j}\left(y_{i t}\right)$ is the probability distribution function of $y_{i t}$ for an individual $i$ in group $j . \pi_{j}$ is the probability of a randomly chosen individual belonging to group $j$. It is formulated by $\pi_{j}=\frac{e^{\theta_{j}}}{\sum_{j=1}^{j} e^{\theta_{j}}}$. Since there are no predictors for group membership included, $\theta_{j}$ is referred to as a set of base parameters estimated from the multinomial logit model.
The analyses are conducted using SAS 9.2. Respondents are assigned to the trajectory for which they have the largest posterior probability estimate - the group that best conforms to the individual's observed alcohol use severity. Subjects with a high probability (i.e., $p \geq 0.7$ ) of a specific trajectory group were included from further analyses because they were considered correctly assigned to a specific alcohol use groups. Bayesian Information Criterion $(B I C)^{i}$ is used to determine the optimal number of trajectory groups that describes the data (Jones et al., 2001) (see Table 2). The analyses examined models for three through seven trajectory groups, with consideration of cubic, quadratic, and linear forms. The procedure initially specified cubic functions for the trajectories, the most general and default option, and the Quadratic or linear forms were utilized in instances where an improvement in fit was noted. Trajectory groups with less than $10 \%$ of the sample were considered problematic and rejected (Jones et al., 2001). The approach then uses a multinomial modeling strategy (estimating the parameters of finite mixture models by maximum likelihood) to compare the groups on various predictor variables (Jones et al., 2001). The likelihood for the entire sample is formulated as $L=\prod^{N} p\left(Y_{i}\right)$, it is the product of the individual likelihood functions of the $\mathrm{N}$ individuals who make up the sample, $p\left(Y_{i}\right)$. With the addition of covariates in the model, $\pi_{j}$ is now formulated as $\pi_{j}\left(x_{i}\right)=\frac{e^{x_{i} \theta_{j}}}{\sum_{j} e^{x_{i} \theta_{j}}}$, where $x_{i}$ is the vector for the potential predictors that are associated with a specific group $j$ in the model and $\pi_{j}\left(x_{i}\right)$ is the probability of belonging to group $\mathrm{j}$ conditional on $x_{i}$. It is much more flexible than hierarchical linear modeling because it allows cross-group differences in the level and shape of trajectories (Jones et al., 2001). Group-based modeling is appropriate for this study because it seeks to understand how multiple distinct patterns of alcohol use change over time and to predict who is likely to belong to a particular trajectory class. 


\section{Table 2. Model fit indices, HRS 1994-2008}

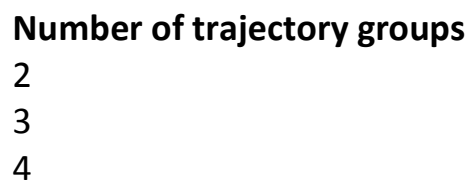

Males ( $\mathrm{N}=\mathbf{1 1}, \mathbf{7 4 2})$

$-79,240.62$

$-73,209.68$

$-72,974.69^{*}$

\author{
Females $(\mathrm{N}=15, \mathbf{4 8 2})$ \\ $-75,440.25$ \\ $-68,731.48^{*}$ \\ $-67,429.17$
}

\section{Analysis Plan}

Two regression models were estimated for the dependent variable. Since the purpose of this study is to examine the impact of marital status transition on alcohol consumption, the first model only included marital history. The second model built upon the first model to add age, race, education, and marital history. It has been well established in every society that men drink more than women (Wilsnack et al., 2000; Holmila \& Raitasal, 2005; Emslie, Lewars, Batty, \& Hunt, 2009) even though the adverse consequences of alcohol abuse are greater in women, because they are more sensitive to raised blood alcohol levels after a shorter period of drinking smaller amounts of alcohol than for men (Brady \& Randall, 1999). Therefore, two separate but identical regression models - one for males and the other for females - will be estimated.

\section{Results}

\section{Descriptive Statistics}

In both the male and female samples (see Table 3), more than 80 percent of the sample was white and more than 70 percent of the sample had at least a high school education. Most respondents (85 percent for men and 74 for women) remained married. On average, respondents were 75 years of age. The average posterior assignment probabilities for each group (provided upon request) indicate that 91-96\% of elderly men and $96-98 \%$ of elderly women were correctly assigned to different depression groups.

\section{Table 3. Descriptive Statistics}

No marital transition

Always married/partnered ${ }^{*}$

Never married

Always divorced ${ }^{*}$

Always widowed ${ }^{*}$

Experienced transition

Marriage to divorce*

Marriage to widowed ${ }^{*}$

Single/Divorced/Widowed to married ${ }^{*}$

Age in 1994

Race

White

Black $^{*}$

Hispanic

Education

Less than high school

High School or GED*

Greater than high school ${ }^{*}$

${ }^{*}$ statistically significant at $p \leq .05$

\begin{tabular}{cc}
\multicolumn{2}{c}{ Mean (SD) / \% } \\
Men (N=11,742) & Women (N=15.482) \\
& \\
85.33 & 74.11 \\
0.46 & 0.51 \\
3.69 & 5.50 \\
0.13 & 1.32 \\
& \\
0.65 & 0.50 \\
7.45 & 15.90 \\
2.28 & 2.16 \\
$75.21(12.29)$ & $75.10(13.81)$ \\
& \\
82.76 & 80.08 \\
14.80 & 17.39 \\
2.43 & 2.53 \\
& \\
26.44 & 26.30 \\
32.26 & 37.71 \\
41.30 & 35.99
\end{tabular}




\section{Multivariate analysis}

With respect to alcohol use, four trajectory models were retained as the final model for men and three trajectory group models were retained for women. For men, alcohol use trajectories of Low and Decreasing, Moderate and Fluctuating, and High and Chronic groups were contrasted with those of nondrinkers. For women, alcohol use trajectories of Low and High and Chronic groups were contrasted with those of non-drinkers. Thus, the interpretations for all the parameter estimates are relative to the reference (i.e. non-drinking) group.

\section{Elderly men}

Figure 1 showed that the first trajectory (i.e. Group 1), representing nearly half of the population, may be depicted as a non-drinking group. This trajectory is essentially flat. The second trajectory (i.e.
Group 2), constituting about 21 percent of the population, may be depicted as a Low and Decreasing alcohol use group. It showed a very slight increase in alcohol use from an immediate to the second year, a decline from the second to the sixth year, and tended to stabilize thereafter. The third trajectory (i.e. Group $3)$, constituting nearly 17 percent of the population, may be depicted as a Moderate and Fluctuating alcohol use group. Individuals in this group experienced a drastic increase in alcohol use from an immediate to the second year, followed by a decline from the second to sixth year, and tended to stabilize thereafter. The fourth trajectory (i.e. Group 4), constituting about 16 percent of the population, is a High and Chronic alcohol use group. Individuals in this group experienced a drastic increase in alcohol use from in the first two years, and tended to slightly fluctuate thereafter.

(Figure 1. Group trajectories for alcohol consumption, Elderly Men, HRS 1994-2008

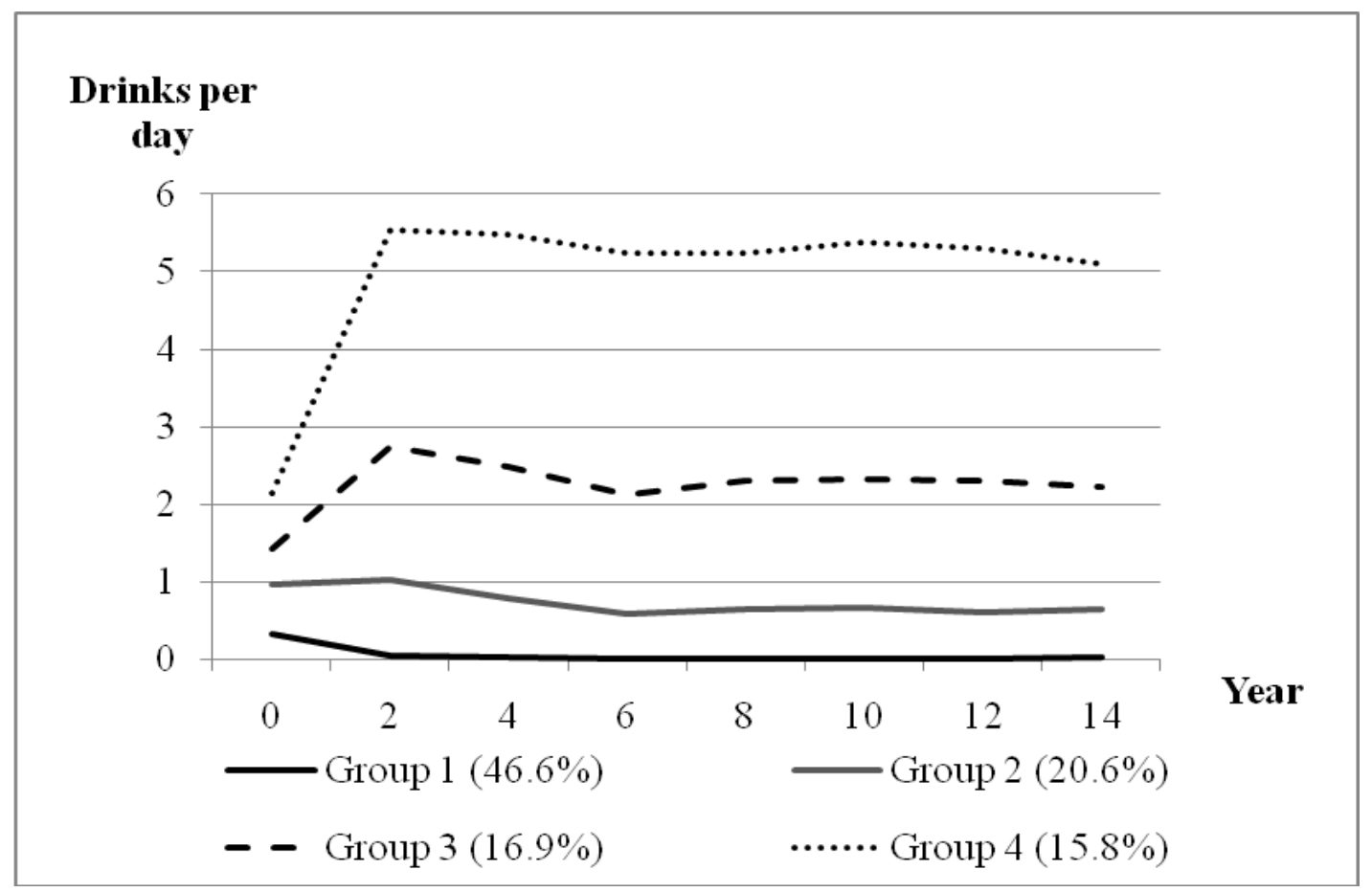

The interpretations for all the parameter estimates are relative to the reference (i.e. non-drinking) group. Elderly men who remained divorced were more likely than their counterparts who remained married to belong to the Low and Decreasing and Moderate and Fluctuating alcohol use groups. Results in models 1 and
2 of Table 4 also suggested that the effect of marital statuses on alcohol use is conditioned by the sociodemographic characteristics of the individuals (age, race, education, the drinking behavior of the deceased spouse) and the pattern of attrition (monotone attrition or variable participation). Results in Model 2 
suggested that elderly men who remained widowed were more likely than their counterparts who remained married to belong to the High and Chronic alcohol use group when these variables were taken into account. Controlling for individual sociodemographic characteristics and pattern of attrition, elderly men who transitioned from marriage to divorced, were less likely to than their counterparts who remained married, to belong to the Low and Decreasing, Moderate and Fluctuating, and High and Chronic alcohol use groups. In contrast, elderly men who became widowed, were more likely than their counterparts who remained married, to belong to the High and Chronic alcohol use group.

As reported in Model 2 of Table 4, the estimates of comorbidity were negative and significant for all alcohol use groups except the High and Chronic group, suggesting that in general, increased number of chronic illnesses is associated with a reduction in alcohol use over time. Results reported in Model 2 also revealed that the likelihood of belonging to the Low and Decreasing, Moderate and Fluctuating, and High and Chronic alcohol use groups decreased with the age. When compared to White men, Black men were more likely to belong to the Moderate and Fluctuating alcohol use groups, but were less likely to belong to the High and Chronic alcohol use group. Hispanic men were more likely than White men to belong to the Low and Decreasing and Moderate and Fluctuating alcohol use groups.

Elderly men with less than a high school education were less likely than their counterparts with a high school or GED education to belong to the Low and Decreasing, Moderate and Fluctuating, and High and Chronic alcohol use groups, while the opposite is observed among their counterparts with education beyond high school. Elderly men who were married to a drinker were more likely to belong to the Low and Decreasing, Moderate and Fluctuating, and High and Chronic alcohol use groups. Monotone (permanent) attritors were less likely than non-attritors to belong to the High and Chronic alcohol use group. Temporary attritors (variable participation) were more likely than non-attritors to belong to the Moderate and Fluctuating alcohol use group.

\section{Table 4. Parameter estimates for depression, elderly men, HRS 1994-2008}

$\begin{array}{llcc}\text { Group } & \text { Parameter } & \text { Model 1 } & \text { Model 2 } \\ \text { Non-Drinker (1) } & \text { Intercept } & -0.160^{* *} & -0.934^{* * *} \\ & \text { Linear } & -0.899^{* * *} & -0.967^{* * *} \\ & \text { Quadratic } & 0.053^{* * *} & 0.056^{* * *} \\ & \text { Comorbidity } & & -0.110^{* *} \\ & \text { Depressive Symptoms } & & -0.035 \\ \text { Low and Decreasing (2) } & \text { Intercept } & 0.040^{* * *} & 0.149 * * * \\ & \text { Linear } & -0.090^{* * *} & -0.108^{* * *} \\ & \text { Quadratic } & 0.004^{* * *} & 0.006^{* * *} \\ & \text { Comorbidity } & & -0.111^{* * *} \\ & \text { Depressive Symptoms } & & 0.002 \\ \text { Moderate and Fluctuating (3) } & \text { Intercept } & 0.806^{* * *} & 0.804^{* * *} \\ & \text { Comorbidity } & & -0.018^{*} \\ & \text { Depressive Symptoms } & & 0.003 \\ \text { High and Chronic }(4) & \text { Intercept } & 1.604^{* * *} & 1.590^{* * *} \\ & \text { Comorbidity } & & 0.021^{* * *} \\ & \text { Depressive Symptoms } & & -0.010^{* *} \\ * * * P<0.001 ; * * P<0.01 ; * P<0.05 & & \end{array}$




\section{Elderly women}

Figure 2 showed that the first trajectory (i.e. Group $1)$, representing nearly 70 percent of the population, may be depicted as a non-drinking group. This trajectory is essentially flat. The second trajectory (i.e. Group 2), constituting about 21 percent of the population, may be depicted as a Low alcohol use group. It showed a very slight increase in alcohol use from an immediate to the second year, a decline from the second to the sixth year, and tended to stabilize thereafter. The third trajectory (i.e. Group 3), constituting nearly 11 percent of the population, may be depicted as a High alcohol use group. Individuals in this group experienced a drastic increase in alcohol use from an immediate to the second year, followed by stabilization thereafter.

Figure 2. Group trajectories for alcohol consumption, Elderly Women, HRS 1994-2008

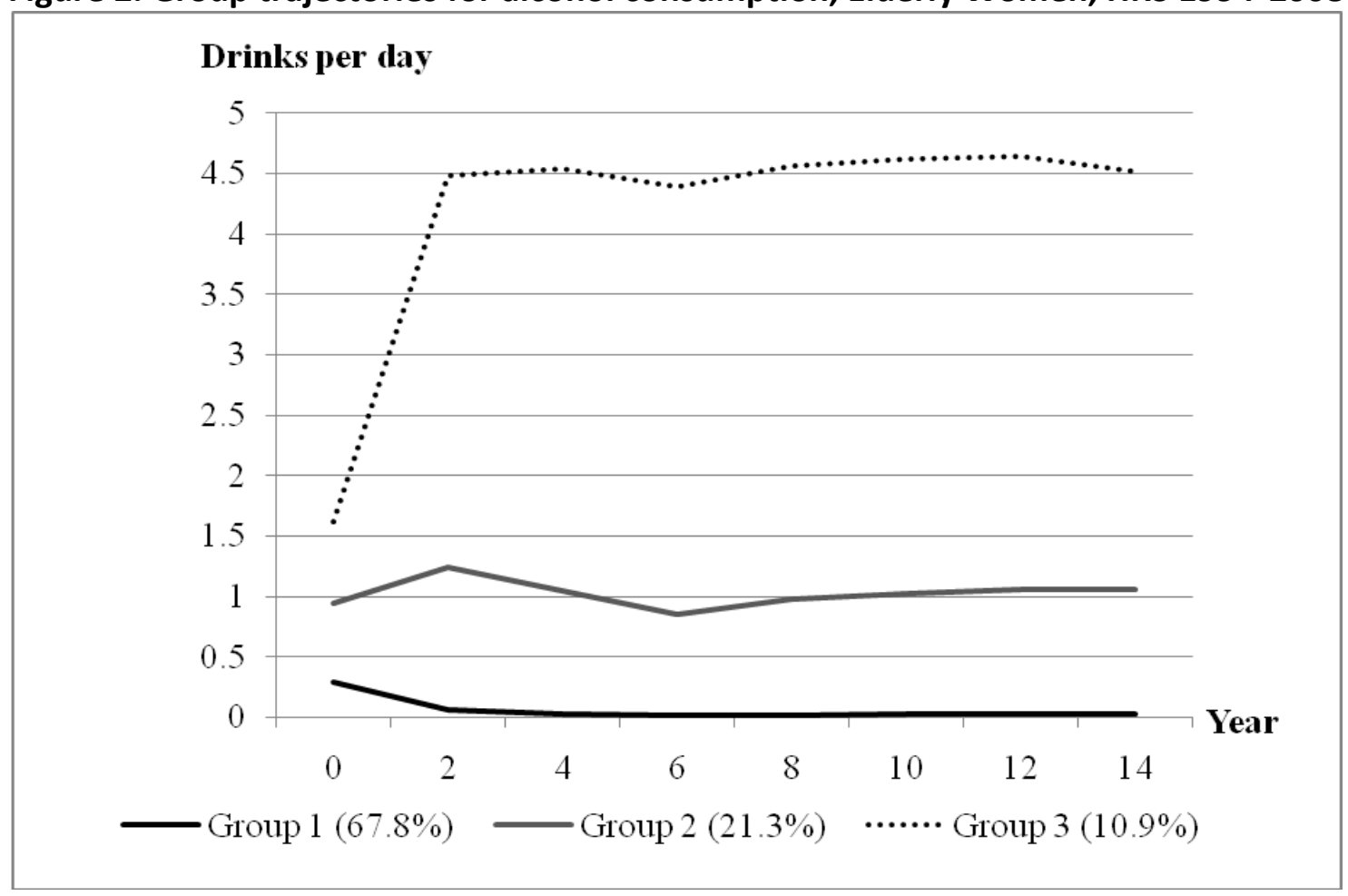

Results in Model 1 of Table 5 revealed that elderly women who remained divorced and elderly women who transitioned from marriage to widowhood were more likely than their counterparts who remained married to belong to the Low and High and Chronic alcohol use groups. Elderly women who remained widowed were more likely than their counterparts who remained married to belong to the Low alcohol use group. Elderly women who transitioned from singlehood, divorce, and widowhood to marriage were more likely than their married counterparts to belong to the Low alcohol use group. However, the effect of transitioning into marriage became insignificant when individual socio-demographic and pattern of attrition were added in Model 2.

As reported in Model 2 of Table 5, the estimates of depression were negative and significant for all alcohol use groups among elderly women. This suggests that an increased number of chronic illnesses is associated with a reduction in alcohol use over time. The estimates for comorbidity were negative and significant for all alcohol use groups except the High and Chronic alcohol use group. This suggests that in general, increased depression is associated with decreased alcohol use for elderly women. 
As reported in Model 2 of Table 5, the likelihood of belonging to the Low alcohol use groups decreased with the age. However, the likelihood of belonging to the High and Chronic alcohol use group increased with age. Black and Hispanic women were less likely than their White counterparts to belong to the Low and High and Chronic alcohol use groups. Elderly women with less than a high school education were less likely than their counterparts with a high school or GED education to belong to the Low and High and Chronic alcohol use groups, while the opposite is observed among their counterparts with education beyond high school. Elderly women who were married to a drinker were more likely to belong to the Low and High and Chronic alcohol use groups. Monotone (permanent) attritors were less likely than non-attritors to belong to the Low and High and Chronic alcohol use group.

\begin{tabular}{|c|c|c|c|}
\hline Group & Parameter & Model 1 & Model 2 \\
\hline \multirow[t]{5}{*}{ Non-Drinker (1) } & Intercept & $-1.279 * * *$ & $-0.916 * * *$ \\
\hline & Linear & $-0.729 * * *$ & $-0.704 * * *$ \\
\hline & Quadratic & $0.043^{* * *}$ & $0.041 * * *$ \\
\hline & Comorbidity & & $-0.215^{* * *}$ \\
\hline & Depressive Symptoms & & $-0.052 * *$ \\
\hline \multirow[t]{5}{*}{ Low (2) } & Intercept & $0.060 * *$ & $0.196 * * *$ \\
\hline & Linear & $-0.020 * *$ & $-0.016 *$ \\
\hline & Quadratic & $0.001 * *$ & $0.002 * *$ \\
\hline & Comorbidity & & $-0.118 * * *$ \\
\hline & Depressive Symptoms & & $-0.011^{*}$ \\
\hline \multirow[t]{5}{*}{ High and Chronic (3) } & Intercept & $0.940 * * *$ & $0.972 * * *$ \\
\hline & Linear & $0.145^{* * *}$ & $0.145 * * *$ \\
\hline & Quadratic & $-0.008 * * *$ & $-0.008 * * *$ \\
\hline & Comorbidity & & -0.009 \\
\hline & Depressive Symptoms & & $-0.015^{* * *}$ \\
\hline
\end{tabular}

\section{Discussion}

Patterns of alcohol consumption across time were relatively stable among the elderly. A similar result was found by Penny Brennan and her colleagues (Brennan, P., Schutte, K., \& Moos, 2010). Findings provide support to the marriage protection effect. Remaining divorced or widowed had detrimental effects on alcohol consumption for elderly men and women. Moderate and high alcohol consumption over time was observed among elderly men who remained divorced. High alcohol consumption over time was observed among elderly men who remained divorced or widowed and among elderly women who remained divorced. This resonates with previous research (i.e. Ekerdt, deLabry, Glynn, \& Davis, 1989; Eng et al., 2005; Power et al., 1999). Indeed, earlier research has established that heavy drinking is related to high levels of stress (Kleinke, Staneski, \& Meeker, 1983) and low levels of social support (Berkman \& Syme, 1979). More recent research also revealed that more frequent visits with family members and friends was predictive of a lower initial level of, and slower rate of change in, alcohol consumption over time (Brennan et al., 2010). A related finding by Stolzenberg (2001) also revealed that spouses, especially wives, tend to play a greater role in the social control of health behaviors and 
maintaining contact with friends and family. Thus, it is possible that these elderly men and women who remained divorce or separated experienced strains associated with household management and changes in the patterns of kin network and social support.

Elderly men who transitioned from marriage to divorce drank significantly less than their counterparts who remained married. Elderly women who transitioned from marriage to widowhood were less likely to become moderate or heavy drinkers compared to the married counterparts. Likewise, having a drinking spouse increased alcohol consumption for both men and women. These findings concurred with those of the earlier studies that acknowledged the potential roles of assortive mating / marital homophily in reducing alcohol consumption following divorce or separation (e.g. Jacob \& Bremer, 1986; Wilsnack et al., 1991; Yamaguchi \& Kandel, 1993). Since marriage can offer individuals a shared lifestyle, alcohol consumption may decrease following the loss of a spouse, especially if the spouse was a drinking partner (Pienta \& Franks, 2006) because these elderly men were removed from their drinking spouses following divorce or separation (Wilsnack et al., 1991) or widowhood.

Age had different effects on drinking trajectories for elderly men and elderly women. Among elderly men, the likelihood of belonging to the Low and Decreasing, Moderate and Fluctuating, and High and Chronic alcohol use groups decreased with the age. However, among elderly women, the likelihood of belonging to the High and Chronic alcohol use group increased with age. Similarly, an earlier study in France also found evidence that women in the oldest generation drank more than the younger women (Zins et al., 1991).

Black and Hispanic men were more likely than Whites to be moderate drinkers. However, Black men were less likely than White men to be heavy drinkers. For women, ethnic minorities were less likely than Whites to be moderate and heavy drinkers. The results corroborate the findings by Stephen Gilman and his colleagues (2008), where Blacks, Asians, and Hispanics have significantly lower odds of alcohol dependence than their white counterparts. Another related finding by Platt, Sloan, and Costanzo (2010) found that Whites were more likely than Blacks to increase alcohol consumption over time. Earlier findings also found that Blacks tended to have lower and later initiation, as well as a slower rate of acceleration into regular alcohol use than Whites (Johnston et al., 1995).

Elderly men and women with education beyond high school have greater likelihood of belonging to the Moderate and High alcohol use groups than their counterparts with a high school or GED education, while the reverse is true for elderly men and women with less than a high school education. This finding resonated with that of Ruchlin (1997), who found a positive association between educational levels and binge drinking. A more recent study by Platt, Sloan, and Costanzo (2010) found an increase in alcohol consumption over time among highly educated individuals.

\section{Implications}

The HRS, however, does not provide information on marital quality (e.g. happiness, satisfaction, sharing of activities, conflict, communication, etc.), family support (e.g. tangible help, emotional attachment, etc.), age of drinking onset, the duration of alcohol consumption, and personality traits. Once more recent, detailed and sufficient data become available, one of the important tasks for future research is to examine the interplay between family support and subsequent alcohol consumption following the death of a spouse, to explore how age of drinking onset and the duration of alcohol consumption affects alcohol use trajectories, and to focus on the ways in which personality traits and marital quality may impact subsequent drinking trajectories among the elderly population.

Information about dementia is not included in the list of number of chronic health conditions in the HRS. Even though it is widely acknowledged that dementia can be a significant problem among the elderly and is related to alcohol consumption, we do not know whether an elderly respondent who participated in the survey has dementia. Once more recent, detailed and sufficient data become available, future researchers should focus on how dementia may impact subsequent drinking trajectories among the elderly population. 
The HRS does not provide information on clinically diagnose depression, and CESD is the only proxy for the presence of depression symptoms in the HRS. The scoring system of the CESD can only be used as an indicator of symptoms relating to depression but not to clinically diagnose depression. Higher scores may indicate that further clinical tests/screenings are warranted, and lower scores do not suggest the absence of clinical depression.

Despite the limitations of the data, this study is a step towards describing and identifying the trajectories, patterns, and changes over time in alcohol consumption, and subsequently identifying the potential predictors of these trajectories. This is more essential than ever, as late-life alcohol use and misuse has become a significant problem among the older adult population, and many elderly people are more vulnerable to the detrimental effects of alcohol (Salmon \& Forester, 2012). Indeed, the number of adults over 50 with any substance abuse problems (alcohol, prescription/ illicit drugs) is projected to triple and the number of older adults needing substance abuse treatment is projected to double in 2020 (Gfroerer, Penne, Pemberton, \& Folsom, 2003). As the United States continues to experience rapid social, economic, demographic, and health changes as baby boomers reach old age, this unique understanding can inform policy makers dealing with health and retirement policies on issues that are pertinent to the elderly widowed population.

Older adults with alcohol abuse and dependence problems are far less likely to be identified as having substance use disorders than younger persons (Blazer and $\mathrm{Wu}, 2009)$. As the needs of the elderly are different from those of younger individuals, the tools used for screening younger populations, such as standard questionnaires and other instruments, may not be adequate for use among the elderly (Beullens \& Aertgeerts, 2004; Nemes et al., 2004). Therefore, few treatment facilities are designed with older adults in mind and are often ill-equipped to meet the specific needs of the elderly, such as the ability to address the limited mobility and access to transportation among patients (Schultz, Arndt, \& Liesveld, 2003). Therefore, health practitioners need to be equipped with the necessary clinical skills to prevent, diagnose, and treat alcohol problems among the elderly. Targeted screening that considers current alcohol consumption, the history of drinking problems, and help-seeking, could help identify older adults at higher risk for excessive or problematic drinking (Moos et al., 2010). Elderly men, Whites, respondents who remained divorced or widowed, and respondents who were married to a drinker, should be the main target of policy interventions designed to reduce alcohol use disorders.

\section{References}

Bachman, J. G., Wadsworth, K. N., O'Malley, P. M., Schulenberg, J., Johnston, L. D. (1997). Marriage, divorce, and parenthood during the transition to young adulthood: Impacts on drug use and abuse. In J. Schulenberg, J. L. Maggs, \& K. Hurrelmann. (Eds.), Health Risks and Developmental Transitions During Adolescence (pp. 246-279). New York: Cambridge University Press.

Berkman, L. F., \& Syme, S. L. (1979). Social networks, host resistance and mortality: a nine year follow-up study of Alameda county residents. American Journal of Epidemiology 109(2),186-204.

Beullens, J., \& Aertgeerts, B. (2004). Screening for alcohol abuse and dependence in older people using DSM criteria: a review. Aging and Mental Health 8(1), 76-82.

Blazer, D. G., \& Wu, L. T. (2009). The epidemiology of substance use and disorders among middle aged and elderly community adults: National survey on drug use and health. American Journal of Geriatric Psychiatry 17(3), 237-245.

Bogart, L. M., Collins, R. L., Ellickson, P. L., Martino, S. C., \& Klein, D. J. (2005). Effects of early and later marriage on women's alcohol use in young adulthood: a prospective analysis. Journal of Studies on Alcohol and Drugs 66(6), 729-737.

Brady, K.T., \& Randall, C. L. (1999). Gender differences in substance use disorders. The Psychiatric Clinic of North America 22(2), 241-252. 
Brennan, P. L., Moos, R. H., \& Kim, J. Y. (1993). Gender Differences in the Individual: Characteristics and Life Contexts of Late-Middle-Aged and Older Problem Drinkers. Addiction, 88(6), 781-787.

Brennan, P., Schutte, K., \& Moos, R. (2010). Patterns and predictors of late-life drinking trajectories: A 10-year longitudinal study. Psychology of Addictive Behaviors, 24(2), 254-264.

Chilcoat, H. D., \& Breslau, N. (1996). Alcohol disorders in young adulthood: effects of transitions into adult roles. Journal of Health and Social Behavior, 37(4), 339-349.

Curran, P. J., Muthen, B. O., \& Harford, T. C. (1998). The Influence of Changes in Marital Status on Developmental Trajectories of Alcohol Use in Young Adults. Journal of Studies on Alcohol and Drugs, 59(6), 647-658.

Dar, K. (2006). Alcohol use disorders in elderly people: fact or fiction? Advances in Psychiatric Treatment, 12, 173181.

Ekerdt, D. J., deLabry, L. O., Glynn, R. J., \& Davis, R. (1989). Change in drinking behaviours with retirement: findings from the normative ageing study. Journal of Studies on Alcohol and Drugs, 50(4), 347-353.

Eng, P. M., Kawachi, I., Fitzmaurice, G., \& Rimm, E. B. (2005). Effects of marital transitions on changes in dietary and other health behaviours in US male health professionals. Journal of Epidemiology and Community Health, 59(1), 56-62.

Emslie, C., Lewars, H., Batty, G. D., \& Hunt, K. (2009). Are there gender differences in levels of heavy, binge and problem drinking? Evidence from three generations in the west of Scotland. Public Health, 123(1), 12-14.

Gfroerer, J., Penne, M., Pemberton, M., \& Folsom, R. (2003). Substance abuse treatment need among older adults in 2020: the impact of the aging baby-boom cohort. Drug and Alcohol Dependence, 69(2), 127-135.

Hajema, K. J., \& Knibbe, R.A. (1998). Changes in social roles as predictors of changes in drinking behavior. Addiction, 93(11), 1717-1727.

Harford, T. C., Hanna, E. Z., \& Faden, V. B. (1994). The long-and short-term effects of marriage on drinking. Journal of Substance Abuse, 6(2), 209-217.

Holmila, M., \& Raitasalo, K. (2005). Gender differences in drinking: why do they still exist? Addiction, 100(12), 17631769.

Jacob, T., \& Bremer, D. A. (1986). Assortative mating among men and women alcoholics. Journal of Studies on Alcohol and Drugs, 47(3), 219-222.

Johnston, L. D., O'Malley, P. M., \& Bachman, J. G. (1995). National Survey Results on Drug Use from the Monitoring the Future Study, 1975-1994. NIH Publication No. 95-4026, Washington: Government Printing Office.

Jones, B. L., Nagin, D., \& Roeder, K. (2001). A SAS Procedure Based on Mixture Models for Estimating Developmental Trajectories. Sociological Methods \& Research, 29(3), 374-393.

Kleinke, C. L., Staneski, R. A., \& Meeker, F. B. (1983). Attributions for smoking behavior: comparing smokers with nonsmokers and predicting smokers' cigarette consumption. Journal of Research in Personality, 17(2), 242255.

Leonard, K. E., \& Rothbard, J. C. (1999). Alcohol and the marriage effect. Journal of Studies on Alcohol and Drugs, Suppl. 13, 139-146.

Matzger, H., Delucchi, K., Weisner, C., \& Ammon, L. (2004). Does marital status predict long-term drinking? Fiveyear observations of dependent and problem drinkers. Journal of Studies on Alcohol and Drugs, 65(2), 255265.

Miller-Tutzauer, C., Leonard, K. E., \& Windle, M. (1991). Marriage and alcohol use: a longitudinal study of "maturing out". Journal of Studies on Alcohol and Drugs, 52(5), 434-440.

Moos, R. H., Schutte, K. K., Brennan, P. L., \& Moos, B. S. (2010). Late-life and life history predictors of older adults' high-risk alcohol consumption and drinking problems. Drug Alcohol Dependence, 108(1-2), 13-20.

Nagin, D. S. (2005). Group-based modeling of development. Cambridge, Massachusetts: Harvard University Press.

Nemes, S., Rao, P. A., Zeiler, C., Munly, K., Holtz, K. D., \& Hoffman, J.H. (2004). Computerized screening of substance abuse problems in a primary care setting: Older vs. younger adults. American Journal of Drug and Alcohol Abuse, 30(3), 627-642. 
Pienta, A. M., \& Franks, M. M. (2006). A closer look at health and widowhood: do health behaviors change after the loss of a spouse? In D. Carr., R. M. Nesse., C. B. Wortman, (eds.), Spousal bereavement in late life (pp. 117142). New York: Springer.

Platt, A., Sloan F. A., \& Costanzo, P. (2010). Alcohol-consumption trajectories and associated characteristics among adults older than age 50. Journal of Studies on Alcohol and Drugs, 71(2), 169-179.

Power, C., \& Estaugh, V. (1990). The role of family formation and dissolution in shaping drinking behavior in early adulthood. British Journal of Addiction, 85(4), 521-530.

Power, C., Rodgers, B., \& Hope, S. (1999). Heavy alcohol consumption and marital status: disentangling the relationship in a national study of young adults. Addiction, 94(10), 1477-1487.

Prescott, C. A., \& Kendler, K. S. (2001). Associations between marital status and alcohol consumption in a longitudinal study of female twins. Journal of Studies on Alcohol and Drugs 62(5), 589-604.

Radloff, L. S. (1977). The CES-D scale: A self-report depression scale for research in the general population. Applied Psychological Measurement, 1(3), 385-401.

Ruchlin, H.S. (1997). Prevalence and correlates of alcohol use among older adults. Preventive Medicine, 26(5, Pt.1), 651-657.

St. Clair, P., Blake, D., Bugliari, D., Chien. S., Hayden, O., Hurd, M., Ilchuk, S., Kung, F. Y., Miu, A., Panis, C., Pantoja, P., Rastegar, A., Rohwedder, S., Roth, E., Carroll, J., \& Zissimopoulos, J. (2010). RAND HRS Data Documentation, Version J. Santa Monica, California: RAND Corporation, RAND Center for the Study of Aging.

Salmon, J. M. \& Forester, B. (2012). Substance Abuse and Co-occurring Psychiatric Disorders in Older Adults: A Clinical Case and Review of the Relevant Literature. Journal of Dual Diagnosis, 8(1), 74-84.

Schultz, S. K., Arndt, S., \& Liesveld, J. (2003). Locations of facilities with special programs for older substance abuse clients in the US. International Journal of Geriatric Psychiatry, 18(9), 839-843.

Stolzenberg, R. (2001). It's about time and gender: Spousal employment and health. American Journal of Sociology, 107(1), 61-100.

Vandecasteele, L., \& Debels, A. (2007). Modelling attrition in panel data: the effectiveness of weighting. European Sociological Review, 23(1), 81-97.

Wilsnack, S. C., Klassen, A. D., Schur, B. E., \& Wilsnack, R. W. (1991). Predicting onset and chronicity of women's problem drinking: a five-year longitudinal analysis. American Journal of Public Health, 81(3), 305-318.

Wilsnack, R.W., Vogeltanz, N. D., Wilsnack, S. C., Harris, T. R., Ahlström, S., Bondy, S., Csémy, L., Ferrence, R., Ferris, J., Fleming, J., Graham, K., Greenfield, T., Guyon, L., Haavio-Mannila, E., Kellner, F., Knibbe, R., Kubicka, L., Loukomskaia, M., Mustonen, H., Nadeau, L., Narusk, A., Neve, R., Rahav, G., Spak, F., Teichman, M., Trocki, K., Webster, I., \& Weiss, S. (2000). Gender differences in alcohol consumption and adverse drinking consequences: cross-cultural patterns. Addiction 95(2), 251-265.

Yamaguchi, K., \& Kandel, D. B. (1993). Marital homophily on illicit drug use among young adults: assortative mating or marital influence? Social Forces, 72(2), 505-528.

Zins, M., Gueguen, A., Leclerc, A., \& Goldberg, M. (1991). Alcohol Consumption and Marital Status of French Women in the GAZEL Cohort: A Longitudinal Analysis between 1992 and 1996. Journal of Studies Alcohol and Drugs, 64(6), 784-789.

\section{Endnote}

\footnotetext{
${ }^{i}$ A criterion for model selection with the purpose of providing a measure of the weight of evidence to select the model that describes the data adequately. It is defined as BIC $=\log (L)-0.5 \mathrm{k} \log (N)$, where $L$ is the value of the model's maximized likelihood, $N$ is the sample size, and $k$ is the number of parameters in the model. The model with the smallest absolute BIC is chosen.
} 